\title{
Going to the Clay: Exploring Conflicts and Values of the Soil in Valparaiso
}

\author{
Keywords \\ Clay, Collective Creation, Material Interdependence, Soil, Urbanisation.
}

This proposition presents a design and artistic research focused on the soil that aims to generate active and poetic forms of reflection around the fragile interdependence of human and non-human lives in an increasingly precarious urban environment, emphasised by the current ecological crisis. In order to engage in such reflections, this practice-oriented research -led by designers, architects, artists and educators - collects relational modes of material interdependence in the region of Valparaíso, Chile, by exploring veins and clay pits for pottery making that are relevant and known by artisans and artists of this area. These spaces are threatened by the increasingly precarious environmental conditions that are exacerbated by the monoculture of the land, the reconstitution of the soil by massive urbanisation projects, and the inaccessibility to clay pits due to the replacement of the commons by the privatisation and exploitation of the land. These urban conflicts generate deterritorialisation that contrasts with the significant relevance and values that these spaces hold for artists, artisans, and other groups, that promote their protection and the respectful interaction with the soil. Against this background, this practice- oriented research explores and expects to make visible the transformation of these lands by following the uses of the soil, identifying conflicts and values that emerge around these extraction sites through immersive sensitive experiences. These immersions into different clay pits consist of walking around, observing the ground, sensing the space, collecting clay from the soil together, sensing and manipulating the material to explore its properties. Thus, by examining the materials, voices and artistic expressions - in the form of poems, sound compositions, images, drawings, photos, cartographies and clay objects- coproduced during four immersions into diverse veins of the Valparaíso Region, we expect to bring back to the fore alternative modes of reflexivity around these sites. This sum of collective experiences for exploration and creation in the veins and clay pits of Valparaíso serves to trace other relational ways of inhabiting, valuing and working with the soil. Therefore, we envisage this practice-oriented research project as a poetic alternative to critically question the modern technocratic logics of urbanisation that operate in the region through the commodification and overexploitation of the land. 